\title{
"Mãe Acha que Bebê Sente Tudo, né?": Concepções Maternas sobre Habilidades Socioemocionais e Comunicativas Infantis
}

\author{
Laísy de Lima Nunes \\ Fabíola de Sousa Braz Aquino \\ Universidade Federal da Paraíba \\ João Pessoa, PB, Brasil \\ Pompéia Villachan-Lyra \\ Universidade Federal Rural de Pernambuco \\ Recife, PE, Brasil
}

\begin{abstract}
RESUMO
A percepção materna e as respostas infantis sobre as emoções, os afetos e a comunicação são importantes para o desenvolvimento inicial de orientação para o mundo. Diante disso, este estudo objetivou identificar como as mães percebem a habilidade do bebê em sentir e expressar emoções. Participaram da pesquisa 20 mães de bebês de 4 meses e 20 mães de bebês de 9 meses. Foi utilizado um questionário sociodemográfico e uma versão adaptada do Infant Intentionality Questionnaire em formato de entrevista. Verificou-se que a maioria das mães percebe seus bebês como sendo capazes de sentir e expressar emoções. Os principais comportamentos relatados pelas mães como formas de expressão emocional infantil foram: choro, sorriso, olhar, expressões faciais, gestos e vocalizações. Espera-se que o conhecimento sobre as percepções maternas acerca de habilidades específicas dos bebês e o acesso a ferramentas metodológicas úteis viabilizem atuações de profissionais na área educacional e de saúde.
\end{abstract}

Palavras-chave: Percepções maternas; Desenvolvimento socioemocional; Habilidades comunicativas; Bebês.

\section{ABSTRACT}

“Does Mother Thinks Baby Feels Everything, doesn't She?": Maternal Conceptions about Children's Socioemotional and Communicative Skills

The maternal perception and infant answers about emotions, affections and communication are important for the initial development of orientation to the world. Thus, this study aimed to identify how mothers perceive the ability of the baby to feel and to express emotions. Participants were 20 mothers of four months babies and 20 mothers of 9 months babies. A sociodemographic questionnaire and an adapted version of the Infant Intentionality Questionnaire in an interview format were used. It was found that most mothers perceive their infants as being able to feel and to express emotions. The main behaviors reported by mothers as forms of child emotional expression were cry, smile, look, facial expressions, gestures and vocalizations. It is expected that knowledge about maternal perceptions of specific skills of babies and the access to useful methodological tools make possible professionals performances in the education and health areas.

Keywords: Maternal perceptions; Socioemotional development; Communication skills; Babies.

\section{RESUMEN}

"Madre Cree que Bebé Siente Todo, ¿no es así?”: Concepciones Maternas acerca de las Habilidades SocioEmocionales y Comunicativas Infantiles

La percepción materna y respuestas infantiles sobre las emociones, los afectos y la comunicación son importantes para el desarrollo inicial de la orientación hacia el mundo. Así, este estudio tuvo como objetivo identificar cómo perciben las madres la capacidad del bebé para sentir y expresar emociones. Los participantes fueron 20 madres de bebés 4 meses y 20 madres de bebés de 9 meses. Se utilizó un cuestionario sociodemográfico y una en una versión adaptada del Infant Intentionality Questionnaire en formato de entrevista. Se encontró que la mayoría de las madres perciben a sus hijos como seres capaces de sentir y expresar emociones. Las principales conductas reportadas por las madres como formas de expresión emocional del niño fueron: llorar, sonrisa, mirada, las expresiones faciales, gestos y vocalizaciones. Se espera que el conocimiento sobre las percepciones maternas de las habilidades específicas de los bebés y el acceso a las herramientas metodológicas útiles hacen posibles actuaciones profesionales en las áreas de educación y salud.

Palabras clave: Percepciones maternas; Desarrollo socioemocional; Habilidades de comunicación; Bebés. 


\section{INTRODUÇÃO}

Este artigo apresenta dados de uma pesquisa mais ampla, que investigou as percepções maternas acerca da habilidade de comunicação intencional dos bebês no primeiro ano de vida, mais especificamente, sobre as habilidades socioemocionais dos bebês, por se constituir como um dos elementos mais marcantes do desenvolvimento comunicativo inicial. Tal habilidade é um marco importante na evolução psíquica infantil por permitir uma participação mais ativa do bebê nos cenários interativos.

Entende-se que no percurso do desenvolvimento infantil ocorrem várias mudanças expressivas, que perpassam o crescimento físico, os avanços cognitivos, emocionais e comunicativos. As respostas infantis sobre as emoções, os afetos e a comunicação são essenciais para o desenvolvimento inicial de orientação para o mundo, tendo em vista a importância do afeto para o desenvolvimento psíquico infantil e a unidade que há na primeira infância entre o afeto e a atividade (Vygotsky, 1996). Desse modo, depreende-se que as relações afetivas também são constituídas nas e pelas interações sociais e marcam o desenvolvimento emocional e da linguagem. No tocante as habilidades iniciais infantis, dada à imaturidade e dependência típica do recém-nascido, a comunicação, por meio da afetividade, proporciona novas formas de compreensão e ação, que lhe permitem realizar atividades diversas, cada vez mais independentes (Trevarthen \& DelafieldButt, 2013).

Considerando o primeiro ano de vida, os bebês têm capacidade de produção e reconhecimento de expressões faciais de emoção, bem como parecem ter preferência pelas interações face a face que envolvem trocas afetivas entre os participantes, além de demonstrarem sensibilidade aos contextos sociais. Estas habilidades infantis são vistas e significadas pelo outro social, que passa a atribuir significado aos comportamentos dos bebês, interpretando-os, mesmo que esse sentido ainda seja ignorado pela criança. As interações sociais em conjunto com as atribuições de significado possibilitam que o bebê tenha contato com o mundo cultural e, gradualmente, seja inserido no universo simbólico e cultural (Vygotsky, 2007).

Nas interações iniciais, a atribuição de significado tem um importante papel para o desenvolvimento infantil, já que a partir dela o bebê internaliza, gradualmente, os significados de vários comportamentos comunicativos e vai se tornando capaz de fornecer respostas para o adulto (Mendes \& Pessôa, 2013a; Nogueira, 2009; Mendes, 2009; Slaughter, Peterson, \& Carpenter, 2009). Comportamentos, como choro, sorriso e gestos, fornecem pistas para que os cuidadores, de modo especial, as mães, interpretem essas ações de acordo com o contexto e com as suas concepções sobre o desenvolvimento infantil e as características específicas dos seus filhos.

Compreende-se que ao atribuir significados aos comportamentos das crianças, as mães revelam parte das suas percepções sobre o desenvolvimento infantil e sobre aspectos específicos desse desenvolvimento, tais como as habilidades socioemocionais infantis. No que tange a esse tema, as concepções parentais têm sido pesquisadas por vários autores (Feldman \& Reznick, 1996; Lopes et al., 2009; Prado, Piovanotti, \& Vieira, 2007; Ribas Jr., Seidl-de-Moura, \& Bornstein, 2007), os quais alegam que elas, enquanto parte do conjunto das crenças, são as bases para o comportamento parental, mesmo que de forma implícita e sem que os pais tenham consciência disso.

Feldman e Reznick (1996) verificaram que alguns bebês podem ser percebidos como menos intencionais e apresentar relativamente menos sinais claros de intencionalidade. Relacionado a isso, autores (Burchinal et al., 2010; Feldman \& Reznick, 1996) advertem que mães que subestimam a habilidade de comunicação intencional infantil podem não estimular apropriadamente seus filhos. Desse modo, um dos fatores mais importantes que justificam o estudo das percepções maternas é a estreita relação entre percepções e práticas. $\mathrm{O}$ modo como as mães veem e compreendem as habilidades socioemocionais e comunicativas infantis norteiam seus comportamentos e cuidados nas interações com os bebês. Além disso, se as mães compreendem a importância das habilidades socioemocionais infantis e ficam atentas aos comportamentos dos bebês, elas podem criar situações que potencializem o desenvolvimento inicial. Estas ações maternas, por sua vez, influenciam o desenvolvimento infantil, demarcando o caráter bidirecional das relações diádicas.

Cabe mencionar que diversos elementos são apontados como fatores que interferem na formulação das percepções parentais e, consequentemente, no modo como as mães interagem com o bebê, são eles: 1. crenças socialmente partilhadas sobre o desenvolvimento, experiências anteriores de familiares e amigos dos pais, e transmissão geracional de práticas educativas (Cabral \& Levandowski, 2012; Marin et al., 2013); 2. conhecimento materno sobre desenvolvimento infantil e características sociodemográficas, tais como idade da mãe, níveis educacional e socioeconômico (Bornstein, Hahn, \& Haynes, 2011; Ribas Jr. et al., 2007); 3. as percepções de mães adolescentes sobre as habilidades do bebê e sobre a própria mater- 
nidade (Levandowski, Piccinini, \& Lopes, 2008; Marin \& Levandowski, 2008).

Contudo, tendo em vista os diversos fatores que podem influenciar as percepções parentais, ressalta-se que não existe uma relação de causalidade linear entre esses elementos e tais concepções, e sim que eles estão entrelaçados em uma cadeia de influência.

Considerando a relevância dessa temática, e a escassez de trabalhos que abordem, especificamente, as percepções maternas acerca das habilidades socioemocionais infantis, esse trabalho visa investigar as percepções maternas acerca do desenvolvimento sociemocional de bebês no primeiro ano de vida, com foco na percepção de intencionalidade comunicativa das mães em relação a seus bebês. Especificamente, buscouse identificar como as mães percebem a habilidade do bebê em sentir e expressar emoções; as possíveis variações dessas concepções, considerando o período do desenvolvimento dos bebês; e comportamentos e estados emocionais dos bebês, referidos pelas mães como indicativos de intenção comunicativa.

\section{MÉTODO}

\section{Delineamento e participantes}

Foi realizada uma pesquisa de campo com delineamento transversal. Participaram do estudo 20 mães de bebês de 4 meses e 20 mães de bebês de 9 meses. Foram escolhidas as idades de 4 e 9 meses porque, de acordo com a literatura (Lowe et al., 2012; Tomasello, 2003), é em torno dos 9 meses que emerge no bebê a habilidade de comunicação intencional. No que se refere à idade dos 4 meses, estudos (Feldman \& Reznick, 1996; Tomasello, 2003) referem que este é um período no qual ainda não se observam comportamentos intencionais. Objetivou-se com essa escolha verificar como as mães descreveriam as habilidades dos seus bebês em dois períodos do desenvolvimento que poderiam apresentar configurações distintas acerca do desenvolvimento da comunicação intencional. A idade das mães variou entre 21 e 36 anos, com média 29,23 ( $\mathrm{DP}=4,54)$. Como critérios de inclusão, as mães deveriam ter a idade a partir de 20 anos, serem casadas ou em uma relação estável, residirem em seus próprios domicílios, nas cidades de João Pessoa ou Campina Grande, na Paraíba, com status instrucional a partir do Ensino Fundamental completo e ocupações diversas. Além disso, os bebês deveriam ter nascido a termo e não apresentar problemas no desenvolvimento.

\section{Instrumentos}

Foi utilizado um questionário sociodemográfico e uma versão adaptada do Infant Intentionality
Questionnaire (Feldman \& Reznick, 1996) em formato de entrevista. A nova versão desse instrumento foi proposta pelas pesquisadoras após a tradução do instrumento original, bem como da análise realizada por juízes peritos na área sobre a adequabilidade das questões e da realização de um estudo piloto. No total, essa entrevista é composta de 41 questões, agrupadas em quatro seções. Entretanto, dado os objetivos do presente artigo serão apresentados os resultados de 15 questões, divididas em duas seções, a saber: Percepção materna acerca da consciência dos bebês sobre os próprios estados e Percepção materna acerca da consciência dos bebês sobre os estados dos outros. A primeira seção foi formada pelas seguintes questões: 1. Você acha que seu bebê pode sentir felicidade? 2. Alegria? 3. Amor? 4. Medo? 5. Tristeza? 6. Culpa? 7. Surpresa? A segunda seção abarcou seis questões: 8. Você acha que seu bebê sabe se você teve ou não um dia ruim? 9. Você acha que os bebês podem sentir quando seus cuidadores estão preocupados? 10. Felizes? 11. Tristes? 12. Surpresos? 13. Você acha que os bebês podem reagir à insegurança de suas mães? 14. Você sente que seu bebê tem mais consciência do seu humor do que do humor dos outros? 15. Você acha que seu bebê tem consciência do sofrimento de outra criança? Pontua-se que além de responderem "sim ou não" às perguntas feitas, a maioria das mães emitiu respostas amplas, exemplificando os comportamentos usados por seus bebês para expressar cada sentimento ou reação frente ao sentimento da mãe.

\section{Procedimento para coleta de dados}

A pesquisa foi aprovada pelo Comitê de Ética do Centro de Ciências da Saúde da Universidade Federal da Paraíba (UFPB), através do protocolo de número 0331/12. AAE: 04762412.2.0000.5188. Deste modo, foram considerados todos os procedimento éticos para pesquisa com seres humanos apresentados na Resolução 466/2012 do Conselho Nacional de Saúde. As entrevistas foram realizadas em local reservado, para evitar possíveis interferências. No período compreendido entre agosto de 2012 e janeiro de 2013.

\section{Procedimento para análise dos dados}

Foram levantadas as frequências referentes aos dados do questionário sociodemográfico. As entrevistas foram transcritas de forma literal, em seguida, foi realizada a leitura flutuante e o levantamento das respostas das mães, suas semelhanças e possíveis contradições. Todas as respostas maternas foram qualitativamente analisadas (Bardin, 1977/2002). 


\section{RESULTADOS E DISCUSSÃO}

\section{Percepção materna acerca da consciência dos bebês sobre os próprios estados}

Inicialmente, as mães foram questionadas sobre as emoções e os sentimentos que elas percebem que seus filhos podem sentir. Em relação a essa questão, todas as mães de bebês de 4 meses responderam que seus filhos podem sentir felicidade, e, dessas mães, quatro referiram que os bebês expressam esse sentimento por meio de comportamentos tais como o sorriso e a emissão de sons, como evidenciado no exemplo: "Com certeza. Basta os gritinhos que ela dá." (M5). Dezenove mães desse grupo acham que eles podem sentir alegria. Dezenove mães também responderam que seus bebês podem sentir medo: "Acho. Que, às vezes, ele chora do nada assim, ou ele acorda chorando e não é fome, não é nada, eu acho que é medo. Ele sente!" (M1). Dezessete mães percebem seus filhos como sendo capazes de sentir amor. Duas mães não souberam responder se percebiam seus filhos como sendo capazes de sentir amor.

Ainda no grupo de mães de bebês de 4 meses, dezesseis mães responderam que seus filhos podem ficar surpresos: "Eu acho que sim, pelo... pela expressão facial." (M19). Quinze mães alegaram que seus filhos podem sentir tristeza, tal como nos seguintes exemplos: "Mãe acha que o bebê sente tudo, né?" (M1); "Eu acho que sim, eu acho que desde ontem que ele tá um pouquinho meio que triste." (M6). Uma mãe não soube responder se seu filho era capaz de expressar essa emoção. Em relação à culpa, apenas três mães acreditam que seus bebês podem senti-la.

Já no grupo de mães de bebês de 9 meses, todas responderam que seus filhos podem sentir felicidade, alegria e amor. Dezenove mães responderam que seus bebês podem sentir medo. Dezessete mães responderam que seus filhos podem ficar surpresos: "Sim, quando um brinquedo some e que aparece ela fica surpresa sim." (M20). Uma mãe não soube responder sobre essa emoção. Dezesseis mães alegaram que seus filhos podem sentir tristeza. No tocante à culpa, apenas uma mãe respondeu que seu bebê pode senti-la.

De maneira geral, pode-se verificar que não houve diferença em função da idade dos bebês quanto à percepção materna acerca de seus filhos poderem sentir felicidade e medo; houve maior número de mães de bebês de 9 meses que responderam afirmativamente sobre a capacidade do bebê em sentir alegria, amor, surpresa e tristeza; e, quanto à capacidade do bebê de sentir culpa, o número de mães de bebês de 4 meses que afirmou isso foi maior que o de mães de bebês de 9 meses
Relacionando esses resultados aos dados da literatura concernentes à percepção materna acerca da capacidade dos bebês de sentirem diversas emoções e sentimentos, percebe-se uma congruência, como será discutido. Por exemplo, Jonhson et al. (1982) realizaram um estudo a fim de investigar a percepção materna acerca das seguintes emoções e sentimentos: alegria, surpresa, medo, culpa, tristeza, interesse, raiva, desprezo, timidez, desgosto e angústia. A idade dos bebês desse estudo variou entre 1 e 18 meses; esses bebês foram separados em seis grupos, em função da idade. Aqui serão considerados os grupos 2 e 3 , de bebês entre 4 e 6 meses e entre 7 e 9 meses, respectivamente. No tocante à alegria, todas as mães de bebês de ambos os grupos acreditavam que eles são capazes de senti-la. Tristeza e culpa foram apontados com maior frequência pelas mães de bebês entre 7 e 9 meses. Surpresa e medo foram mais mencionados pelas mães de bebês entre 4 e 6 meses.

Comparados com o presente estudo, esses dados diferem em relação à percepção materna sobre a capacidade do bebê de sentir culpa, surpresa e medo. Todavia, são semelhantes, à medida que a maioria das mães percebe seus bebês como sendo capazes de sentir alegria, tristeza, medo e surpresa. Especificamente sobre a percepção materna acerca de os bebês sentirem culpa, esses autores relacionam isso com alguma projeção por parte da mãe, mas alegam que esse dado também pode refletir expressões infantis rudimentares que se tornam mais bem definidas no segundo ano de vida da criança.

Na pesquisa de Feldman e Reznick (1996), os dados referentes à percepção materna sobre o sentimento infantil mostraram que mais de $75 \%$ das mães entrevistadas no período em que seus bebês tinham 4 e 8 meses não concordavam com a possibilidade de seus filhos sentirem culpa. Esses resultados são congruentes com os que foram aqui encontrados em relação à culpa. Todavia, cabe pontuar que, apesar de a capacidade do bebê de sentir culpa ter sido mencionada por um reduzido número de mães, essa percepção pode ter repercussões nas práticas maternas, inclusive pode fundamentar ações punitivas das mães que visem a castigar o bebê, tendo em vista que, se elas acham que o bebê pode se sentir culpado, é porque consideram que ele sabe que fez algo errado.

Como parte dos resultados concernentes às emoções e aos sentimentos relatados, algumas ações foram mencionadas como sendo utilizadas pelos bebês para expressar o que sentem. Destaca-se que as expressões faciais foram referidas por ambos os grupos de mães. A respeito disso, pesquisas afirmam que, devido às limitações no conjunto de comportamentos 
iniciais infantis, as expressões faciais, assim como os comportamentos vocal e visual, representam um importante comportamento expressivo das emoções dos bebês e refletem o nível de desenvolvimento infantil (Alonso, Morina, Serrano, \& Carriba, 2004; Bornstein et al., 2011; Hoehl \& Striano, 2010; Izard, Woodburn, \& Finlon, 2010; Mendes \& Pessôa, 2013b; Mendes \& Seidl-de-Moura, 2009).

Conforme verificado nos relatos das mães, as expressões faciais, os movimentos corporais e os gestos infantis estão relacionados à atribuição de significado materna, tendo em vista que são pistas comunicativas emitidas pelo bebê para seus cuidadores e predizem o desenvolvimento comunicativo propriamente dito (Camras \& Shutter, 2010; Hoehl \& Striano, 2010). Cabe destacar também que a comunicação fundamenta e relaciona-se com outras funções psicológicas do desenvolvimento infantil. Desse modo, as expressões emocionais do bebê, assim como a capacidade de reconhecer emoções, proporcionam o desenvolvimento da consciência social dos bebês em relação às habilidades de atenção e intenção (Legerstee, 2013; Mendes \& Pessôa, 2013b; Vygotsky, 2007).

Assim, trechos dos relatos maternos encontrados no presente estudo evidenciam a relação existente entre as expressões emocionais, a habilidade comunicativa do bebê e a interação social, tal como exemplificado na fala de uma das participantes do grupo de bebês de 4 meses: "Ele, ele fica na cama, 'falando', né, 'conversando'e alisando meu rosto. Isso pra mim é uma demonstração de afeto, de amor. Eu... pelo menos, é o que eu penso, né." (M6). Esse recorte evidencia como essa mãe percebe os comportamentos comunicativos do bebê, que parecem fornecer pistas para que ela os interprete como uma demonstração de carinho e amor. Esses comportamentos infantis, as interpretações e as atribuições de significado maternas, por sua vez, têm impacto nos contextos interativos (Vygotsky, 2007). Assim, essa questão, além de levantar as percepções maternas acerca dos sentimentos e emoções dos bebês, pode contribuir para ilustrar que os comportamentos, os gestos e as expressões dos bebês são indicadores do seu desenvolvimento, bem como influenciam a maneira como o seu parceiro interacional, no caso a mãe, interage com o bebê.

Especificamente sobre as expressões de alegria e felicidade dos bebês, relatos maternos, tais como "Quando eu chego perto dela, ela abre aquele sorriso, tudo para." (M1, 4 meses) e "(...) e você olha pra ela, ela ri. Você faz uma brincadeira, ela ri, ela dá uma resposta." (M7, 9 meses), demonstram que, na percepção das mães, o sorriso é apresentado como o principal comportamento utilizado para expressar essas emoções. A respeito disso, Mendes (2009) afirma que o sorriso infantil é tido como uma expressão prototípica de alegria e representa uma abertura para o desenvolvimento de emoções positivas.

Sobre a percepção materna acerca da capacidade infantil de sentir medo, apesar de ambos os grupos de mães terem mencionado tal aspecto com a mesma frequência, as mães de bebês de 9 meses apresentaram relatos mais específicos sobre o que as fazem pensar que os bebês sentem medo, tal como no exemplo: “(...) mas eu acho que ela tem medo de escuro." (M7). Esse resultado confirma dados da literatura que alegam que, à medida que o bebê cresce, o medo da escuridão também aumenta, isso porque o escuro provoca nele a sensação de isolamento e solidão. Esta explicação ganha apoio no estudo de Tuan (2005), o qual verificou que, próximo aos 10 meses, os bebês preferem explorar ambientes bem iluminados. Ainda sobre a capacidade infantil de sentir medo, Bussab (2000) lembra que o medo de estranhos está presente nos bebês desde os primeiros meses de vida, ainda que de forma sutil. Entretanto, entre os 8 e 12 meses, esse medo se torna mais agudo e é expresso de modo mais revelador.

Com relação à capacidade dos bebês de ficarem surpresos, também se verificou uma diferença qualitativa entre os relatos das mães dos dois grupos. Entre as mãe de bebês de 9 meses, foi referido que a brincadeira de "aparecer-desaparecer" é um dos contextos específicos no qual a criança demonstra surpresa. Resultados semelhantes foram apresentados por Braz Aquino (2008), ao observar díades mãe-bebê em situação de brincadeira livre. Essa autora observou que, aos 9 meses, os bebês exibiram novas modalidades sociocognitivas por meio do uso de brincadeiras em contextos de mediação, tais como jogos de "aparecer e desaparecer", que atraíam a atenção dos bebês e faziam com que eles dirigissem seus sorrisos às mães. Ademais, as percepções maternas acerca dessas novas aquisições infantis mobilizam a criação de brincadeiras diversas e o uso de brinquedos inéditos. Diante desses dados, ressalta-se, ainda, que as manifestações de emoções por parte do bebê e a percepção das mães sobre isso possibilitam e potencializam as relações interpessoais.

\section{Percepção materna acerca da consciência dos bebês sobre os estados dos outros}

Outro aspecto investigado foi a percepção materna acerca do conhecimento dos bebês sobre os estados dos outros, ou seja, como o bebê reconhece as emoções e lê a intenção do outro. A primeira questão desta seção foi "Você acha que seu bebê sabe que você teve ou não um dia ruim?". Quinze das vinte mães de bebês de 4 meses responderam 
que seus bebês sabem reconhecer se elas tiveram ou não um dia ruim e que, na maioria das vezes, o humor materno percebido pelo bebê também influenciará o comportamento deste, como no exemplo a seguir: "Acho, porque ela percebe o humor da gente e transfere pra ela." (M9). Cinco outras mães desse grupo têm uma percepção diferente e alegam que seus bebês são muito novos para saber reconhecer isso.

Já entre as mães de bebês de 9 meses, 12 mães acham que seus bebês sabem se elas tiveram ou não um dia ruim e que o humor delas é refletido no comportamento do bebê. "Eu acho que sim, ela sente. Ela sente e fica mais, mais emotiva, já notei. Mais estressadinha quando eu tiver mais estressada. Ela fica mais calma quando eu tô mais calma." (M11). Oito mães desse grupo acham que os bebês ainda não têm essa percepção. Os relatos maternos sobre essa questão estão diretamente relacionados aos dados da questão seguinte e serão discutidos conjuntamente, na sequência. Na ocasião, será discutida essa habilidade do bebê de reconhecer os estados e o humor dos outros e apresentadas as implicações disso nas configurações interativas.

Foram analisadas às percepções maternas acerca da consciência que os seus bebês têm dos sentimentos e emoções dos seus cuidadores, mais especificamente, se as mães acham que os bebês podem sentir quando seus cuidadores estão felizes, tristes, preocupados $e$ surpresos.

A maioria das mães de bebês de 4 meses acredita que os bebês podem sentir o humor dos seus cuidadores, entretanto, existem algumas diferenças, dependendo de qual emoção o cuidador expressa. Assim, 19 mães acham que seus bebês podem sentir quando os cuidadores estão tristes, como demonstrado no exemplo: "A tristeza, já vem aquela coisa que você não tem o riso pra dar, você não tem uma alegria, eu acho que eles percebem." (M11). Já 18 mães acham que os bebês sentem quando seus cuidadores estão felizes: "Podem, por causa da felicidade que a gente passa pra eles." (M11). Também 18 mães afirmaram que eles sentem quando os cuidadores estão preocupados: "Eu acho que, quando a gente não tá bem, a gente transmite, a gente não transmite paz. Eu acho que a criança fica mais agitada." (M13). Por fim, 13 mães acreditam que seus bebês sentem quando os cuidadores estão surpresos: "Eu acho que eles sentem. (...) Eu acho que eles reagem com choro." (M16).

No tocante às mães de bebês de 9 meses, todas elas acham que seus bebês sentem quando seus cuidadores estão felizes, como pode ser visto no exemplo: "Acho que é mais fácil eles sentirem quando a gente tá feliz." (M4). Nesse grupo, 15 mães acham que eles sentem quando seus cuidadores estão tristes: "É lógico que ele percebesse a tristeza também, né." (M16). Também 15 mães acham que os bebês sentem que os cuidadores estão preocupados: "Preocupados? Sim, eu me agoniei com ela, quando ela tava doente (...). Ela viu, eu chorei, ela viu que eu tava chorando e ela fez um bico porque eu tava chorando." (M7). Já 11 participantes acreditam que eles sentem quando os cuidadores estão surpresos, "Surpresos? É, ela imita, né, quando a gente tá surpreso, ela meio que imita, né. Acho que tem como ela perceber." (M3).

Os relatos maternos apresentados nas duas questões descritas nesta seção confirmam discussões apresentadas em pesquisas na área do desenvolvimento infantil (Bornstein, 2013; Legerstee, 2013; Mendes \& Seidl-de-Moura, 2009; Mendes \& Pessôa, 2013a, $2013 b$ ), que consideram o primeiro ano de vida como um período crucial para o desenvolvimento emocional, relacionado à capacidade do bebê de produzir expressões emocionais e reconhecê-las. O desenvolvimento dessas habilidades mais complexas permite que os bebês leiam e interpretem os sentimentos e estados dos outros. Assim, esses resultados também estão articulados aos resultados da pergunta sobre a percepção materna acerca da habilidade dos bebês de comunicarem suas emoções, anteriormente apresentados e discutidos neste trabalho.

Semelhante aos resultados aqui encontrados, a literatura mostra que desde tenra idade os bebês têm capacidade de identificar, nos outros, algumas expressões faciais que estão associadas às emoções (Mendes \& Seidl-de-Moura, 2009; Nelson \& Horowitz, 1983; Trevarthen, 2011). Cleveland et al. (2007) defendem que, com apenas 3 meses, os bebês parecem reagir de acordo com as emoções e os comportamentos do adulto, inclusive com os movimentos de direção do olhar. Todavia, esses autores destacam que essa percepção infantil e os comportamentos direcionados aos comportamentos do adulto tornam-se mais robustos e elaborados, especialmente, em torno dos 9 meses. Hoehl e Striano (2010) constataram que bebês a partir de 7 meses são capazes de discriminar e classificar emoções básicas manifestadas pelas expressões faciais dos adultos.

Markova e Legerstee (2008) demonstram que os bebês percebem as interações com seus cuidadores como um sistema regulado mutuamente, no qual ambos se engajam em trocas afetivas e têm os significados de suas expressões emocionais apreciados pelo outro. Além disso, as autoras sugerem que os bebês não apenas percebem as emoções dos seus cuidadores, mas também reagem de acordo com elas. Essa ideia é corroborada por resultados encontrados no presente 
estudo e pode ser ilustrada no trecho da fala de uma mãe do grupo dos bebês de 9 meses: "Eu acho que ele consegue sentir a energia, se a coisa não tá muito bem, se tá ruim, eles ficam mais quietinhos." (M6).

Fundamentadas no pressuposto de que os bebês percebem e reagem diante das emoções dos seus cuidadores, Legerstee e Markova (2007) realizaram um estudo com bebês de 3, 6 e 9 meses, no qual as díades mãe-bebê foram filmadas em três condições de interação, quais sejam: face a face, face estática e face estática modificada (a mãe usando uma máscara). Os resultados encontrados demonstraram que os bebês estão conscientes dos aspectos relacionais da emoção e da comunicação. Isto porque, nos três grupos, os bebês produziram, significativamente, mais afetos positivos durante a interação natural face a face e responderam com mais afetos negativos durante a condição clássica de face estática.

Outra pesquisa que utilizou o paradigma da face estática, realizada por Lowe e colaboradores (2012), mostrou que as alterações das expressões emocionais no adulto têm efeito no comportamento do bebê com quem interage. Nesse estudo, tanto bebês de 4 meses quanto de 9 meses perceberam as variações no comportamento materno e reagiram de acordo com o que foi percebido. Dessa forma, evidencia-se o caráter bidirecional das interações diádicas, nas quais os comportamentos do bebê são influenciados não apenas pelo seu próprio estado emocional e por suas próprias intenções, mas também pelo que é percebido por ele a respeito do parceiro social.

Nesse sentido, autores (Mendes \& Pessôa, 2013b; Mendes \& Seidl-de-Moura, 2009) indicam que as habilidades sociocomunicativas infantis ampliam-se em função dos comportamentos maternos nos contextos interativos. Esses autores argumentam que as ações infantis dependem também do que os bebês percebem sobre as emoções do parceiro social e da dinâmica da comunicação afetiva nas interações estabelecidas. Ademais, as relações emocionais estabelecidas entre o bebê e seu cuidador ajudam a compreensão infantil sobre "como" e "o que" as pessoas pensam, o que é fundamental para a compreensão das intenções dos outros, para o desenvolvimento da habilidade de comunicação intencional e da compreensão e orientação para o mundo (Markova \& Legerstee, 2008). Legerstee (2013) defende que, ao longo do desenvolvimento, o bebê percebe o outro como sendo semelhante a ele mesmo (like me) e, ainda mais importante, desenvolve a consciência de que o outro está emocionalmente envolvido com ele (with me). Essa habilidade permite que o bebê perceba as emoções dos cuidadores e interaja a partir disso, confirmando a sensibilidade infantil para as contingências sociais (Trevarthen \& Delafield-Butt, 2013).

A questão seguinte foi "Você acha que os bebês podem reagir à insegurança de suas mães?" Sobre essa pergunta, 15 mães de bebês de 4 meses responderam afirmativamente: "Podem, eu acho que eles sentem quando você tá insegura e eles reagem. Ou eles reagem de forma a enfrentar essa sua insegurança ou eles recuam." (M6). Quatro mães acreditam que seus bebês ainda não têm essa habilidade por conta da pouca idade. Uma mãe não soube responder a questão. No grupo de mães de bebês de 9 meses, 18 acham que seus bebês podem reagir à insegurança materna. Duas mães acham que os bebês não são capazes de perceber a insegurança das mães e, consequentemente, não são capazes de reagir.

Sobre a capacidade do bebê de reagir à insegurança materna, notou-se que, apesar do elevado número de mães de bebês de 4 meses que respondeu afirmativamente, a frequência dessas respostas entre mães de bebês de 9 meses foi superior. Este dado está relacionado à questão anterior sobre a habilidade dos bebês de perceberem as emoções maternas e demonstra que aos 9 meses essa habilidade está mais consolidada. Sobre esse aspecto, Lowe et al. (2012) mostram que os estilos maternos responsivos estão associados a comportamentos positivos do bebê. Entretanto, em experimentos realizados em laboratório, bebês cujas mães demonstram mais insegurança e traços de ansiedade apresentam comportamentos mais negativos e alterações de humor.

$\mathrm{Na}$ sequência, foi perguntado às participantes: "Você sente que seu bebê tem mais consciência do seu humor do que do humor dos outros?". Das 20 mães de bebês de 4 meses, 17 responderam "sim" e justificaram suas afirmações alegando que, por serem mais próximas dos filhos e passarem a maior parte do tempo com eles, os bebês têm mais facilidade em perceber o humor materno, como no exemplo: " $A$, com certeza, porque nós somos o primeiro contato, o contato mais próximo que ele tem é com a gente, né, com a mãe principalmente." (M13). Uma mãe respondeu que seu filho tem mais consciência do humor da babá, tendo em vista que ele passa mais tempo com esta, como ilustrado no exemplo: "Eu acho que ele hoje, ele tem consciência mais do da babá do que do meu, porque ele convive mais com ela." (M1). Uma mãe disse que seu bebê percebe igualmente o humor materno e o dos outros. Outra mãe não soube responder e afirmou nunca ter prestado atenção a esse tipo de comportamento do seu bebê.

Entre as mães de bebês de 9 meses, 18 acham que seus filhos têm mais consciência do seu humor 
do que do humor de outras pessoas e apresentaram os mesmos argumentos que as mães de bebês de 4 meses para justificar suas respostas. Uma mãe respondeu que sua filha tem mais consciência do humor da babá. Outra mãe acha que sua filha percebe o humor de todos de maneira uniforme, a depender de como a pessoa fala com ela, independentemente de ser a mãe ou uma pessoa desconhecida.

Em congruência com os relatos das participantes, estudos (Bornstein, 2013; Legerstee, 2013; Mendes \& Seidl-de-Moura, 2009; Mendes \& Pessôa, 2013a, 2013b) revelam que os bebês têm a habilidade de reconhecer o humor dos seus cuidadores, porém, para que isso ocorra, faz-se necessário o engajamento do bebê com o outro social. Desse modo, a mãe, enquanto cuidadora primária, tende a estar mais tempo e a interagir mais com o bebê, o que permite que eles se engajem de forma mais sólida, envolvendo aspectos emocionais, comunicativos e sociais. Isto favorece para que o bebê perceba mais o humor da mãe do que o de outras pessoas. Todavia, também merecem destaque as respostas maternas que pontuaram que o bebê percebe mais o humor da babá. Este dado ilustra uma das diversas configurações possíveis que caracterizam a família e as relações de cuidado na atualidade. É cada vez mais comum que as mães, já nos primeiros dias e meses de vida do bebê, deleguem o cuidado com seus filhos a babás e avós, para retornarem às suas atividades profissionais (Prado et al., 2007). Desse modo, alguns bebês podem passar mais tempo com as babás, o que parece permitir um engajamento maior com essa cuidadora.

Também foi perguntado: "Você acha que seu bebê tem consciência do sofrimento de outra criança?". Cinco mães de bebês de 4 meses acham que seus filhos percebem o sofrimento de outra criança, como demonstrado no exemplo seguinte: "Sim, porque quando, outro dia, tinha um bebê chorando e ela ficou assim assustada. Eu acho que sim." (M3). Catorze responderam que eles ainda não possuem essa habilidade. Uma mãe não soube responder essa questão.

Entre as mães de bebês de 9 meses, 11 afirmaram que eles têm consciência do sofrimento de outra criança e que isso, algumas vezes, pode ser percebido pela mudança que ocorre nos comportamentos dos bebês ao verem outra criança chorando, como no exemplo: "Quando ele vê uma criança chorando, ele, ele assim, ele até às vezes faz biquinho pra chorar. Eu acho que ele entende que aquilo ali é que tá fazendo mal para a criança, alguma coisa, né? Eu acho sim." (M1). Oito mães responderam que seus bebês ainda não têm essa habilidade. Uma mãe respondeu que, apesar de sua filha prestar muita atenção quando vê outras crianças chorando, ela não sabe responder se isso significa que a filha entende que a criança está sofrendo.

No tocante a essa questão, houve um maior número de mães de bebês de 9 meses que percebe seus filhos como tendo consciência do sofrimento de outras crianças. As justificativas maternas para essa questão remetem, geralmente, ao comportamento "imitativo" dos bebês ao verem outra criança chorando. Relacionado a isso, Amorim et al. (2012) afirmam que, desde os meses iniciais de vida, o bebê tem interesse por outras crianças, ele as observa por períodos prolongados de tempo e gosta da sua companhia. Isto contribui para que, ao final do primeiro ano, os bebês estejam mais aptos a perceberem os estados dos outros e se comportarem de acordo com o que percebem no contexto.

As respostas de parte das mães a essa questão têm apoio em estudos que demonstram a capacidade de empatia em bebês, a qual, segundo Legerstee (2013), é possibilitada por circuitos neurais e pelas experiências socioemocionais e sensoriais. Sobre isso, Knafo e Uzefovsky (2013) apresentam evidências da existência do sentimento infantil de empatia, que está diretamente relacionado ao engajamento socioemocional do bebê com os outros. Essas considerações permitem identificar a estreita relação da empatia com a intersubjetividade, como indicada também por Amorim et al. (2012) e Costa (2012) nas relações dos bebês com seus pares. Essas autoras apresentam episódios envolvendo bebês em ambientes de creches e defendem que, mesmo em tenra idade, os bebês têm uma percepção interpessoal e apresentam empatia, que é considerada um elemento mediador de comportamentos de ajuda ao outro. Nesse sentido, Bussab et al. (2007) afirmam que o choro dos bebês em resposta ao choro de outras crianças pode ser entendido como um precursor da ação empática, que se apresenta ainda no primeiro ano de vida do bebê.

\section{CONSIDERAÇÕES FINAIS}

O presente estudo buscou conhecer as concepções maternas acerca do desenvolvimento sociemocional de bebês no primeiro ano de vida. As habilidades que compõem esse aspecto do desenvolvimento, tais como o reconhecimento de emoções e as expressões socioemocionais, são construídas a partir da atividade cognitiva e da interação social. Nessa linha, justifica-se a relevância de trabalhos que investiguem a compreensão das mães sobre essa área do desenvolvimento, tendo em vista que isso pode influenciar diretamente a qualidade da interação que estabelece com seus filhos. 
Diante do exposto e com base nos resultados apresentados, foi possível verificar que a maioria das mães, em ambos os grupos, percebe seus bebês como sendo capazes de sentir e expressar emoções. Em consonância com a literatura nessa área, foram descritos pelas mães comportamentos, tais como o choro, o sorriso, as diversas configurações do olhar, as expressões faciais, os gestos e as vocalizações, habilidades e situações que evidenciam o potencial sociocomunicativo das emoções dos bebês para a constituição da habilidade comunicativa intencional infantil. Desse modo, os elementos apresentados nos relatos maternos contribuem para entender melhor o conjunto de habilidades que compõem a cognição social infantil, de maneira especial, o desenvolvimento socioemocional, dado que evidenciam o modo como o bebê expressa suas emoções, compreende e responde aos estados emocionais dos seus parceiros.

Ressalta-se a importância dada pelas mães às expressões faciais dos bebês como um dos principais meios comunicativos, tendo em vista que a linguagem oral ainda não foi desenvolvida. Nesse sentido, os dados da presente pesquisa corroboram ideias apresentadas pela literatura na área, segundo as quais as expressões faciais, bem como os comportamentos vocais e visuais, têm um papel relevante na comunicação inicial e revelam traços de intencionalidade comunicativa antes do surgimento da fala (Amorim, et al., 2012; Camras \& Shutter, 2010; Cleveland et al., 2007).

No tocante às percepções maternas acerca da consciência dos bebês sobre os estados dos outros os resultados evidenciaram, segundo a maioria das mães, que os bebês percebem diferenças no humor dos seus cuidadores. Para elas, seus bebês são capazes, ainda aos 4 meses, de reconhecer estados de felicidade, tristeza, preocupação e surpresa, e respondem de acordo com as emoções percebidas. Esses dados, assim como os que são apresentados em outros estudos (Hoehl \& Striano, 2010; Markova \& Legerstee, 2008) ratificam a postura ativa do bebê nas interações sociais e ilustram o pressuposto das interações como mutuamente reguladas.
Considera-se relevante mencionar ainda que este estudo, além de apresentar dados empíricos sobre a percepção materna acerca da habilidade intencional de bebês de 4 e 9 meses, propõe um conjunto de questões adaptadas semanticamente, a partir do Infant Intentionality Questionnaire (Feldman \& Reznick, 1996). Trata-se de um instrumento que pode ser utilizado por psicólogos e pesquisadores do desenvolvimento inicial, com o intuito de realizar uma análise mais aprofundada acerca do domínio sociopragmático e intencional da linguagem e captar de forma mais ampla as percepções maternas acerca da habilidade de comunicação intencional infantil.

Espera-se que o conhecimento sobre as percepções maternas acerca de habilidades específicas dos bebês e o acesso a ferramentas metodológicas úteis viabilizem atuações de profissionais na área educacional e de saúde que visem identificar, precocemente, possíveis configurações atípicas nas dimensões sociocomunicativas e afetivas, que interfiram na relação posterior da criança com seu entorno.

Além disso, é importante mencionar que os resultados apresentados precisam ser considerados com cautela, devido ao número restrito de participantes, às características peculiares do contexto sociocultural no qual elas estão inseridas e às especificidades de cada fase do desenvolvimento dos bebês. Nesse sentido, os resultados são entendidos como um recorte singular que considerou as características próprias de cada mãe e que não permite generalizações.

Por fim, sugere-se que futuros estudos possam ter maior número de participantes, de variados níveis socioeconômicos e em contextos distintos, bem como possam incluir mães em diferentes etapas da vida (adolescentes e adultas) e bebês em outras fases do desenvolvimento (por exemplo, recém-nascidos). Ademais, indica-se a realização de pesquisas que investiguem essa temática com outros cuidadores infantis, tais como pais, avós, babás e educadores, que podem fornecer dados e subsídios para melhor compreensão das percepções e das interações entre os bebês e seus cuidadores secundários, que também têm importante papel no desenvolvimento infantil.

\section{REFERÊNCIAS}

Alonso, A. L., Molina, F. C., Serrano, J. M., \& Carriba, S. F. (2004). Neuropsicología de la percepción y la expresión facial de emociones: Estudios con ni-os y primates no humanos. Anales de psicologia, 20(2), 241-259.

Amorim, K. S., Costa, C. A., Rodrigues, L. A., Moura, G. G., \& Ferreira, L. D. P. M. (2012). O bebê e a construção de significações, em relações afetivas e contextos culturais diversos. Temas em Psicologia, 20(2), 309-326. http://dx.doi. org/10.9788/TP2012.2-03 
Bardin, L. (2002). Análise de conteúdo. Trad. L. Antero Neto e A. Pinheiro. São Paulo: Livraria Martins Fontes. (Originalmente publicado em 1977).

Bornstein, M. H. (2013). Mother - Infant Attunement: A Multilevel Approach via Body, Brain, and Behavior. In M. Legerstee, D. Haley, \& M. H. Bornstein (Eds.). The Infant Mind: Origins of the Social Brain (pp. 266-289). New York: Guilford Press.

Bornstein, M. H., Hahn, Chun-Shin, \& Haynes, O. M. (2011). Maternal personality, parenting cognitions, and parenting practices. Developmental Psychology, 47(3), 658-675. http://dx.doi.org/10.1037/a0023181

Braz Aquino, F. de S. (2008). Intencionalidade comunicativa e atenção conjunta: uma análise em contextos interativos mãe-bebê (Tese de Doutorado). Universidade Federal da Paraíba, João Pessoa.

Burchinal, M., Skinner, D., \& Reznick, J. S. (2010). European American and African American mothers' beliefs about parenting and disciplining infants: a mixed-method analysis. Parenting: Science And Practice, 10, 79-96. http://dx.doi. org/10.1080/15295190903212604

Bussab, V. S. R. (2000). A família humana vista da perspectiva etológica: natureza ou cultura? Interação em Psicologia, 4, 9-22.

Bussab, V. S. R., Pedrosa, M. I., \& Carvalho, A. M. A. (2007). Encontros com o outro: empatia e intersubjetividade no primeiro ano de vida. Psicologia USP, 18(2), 99-133. http://dx.doi.org/10.1590/S0103-65642007000200007

Cabral, S. \& Levandowski, D. (2012). Representações de mães adolescentes: aspectos intergeracionais na relação mãecriança. Fractal, 24(3), 543-562. http://dx.doi.org/10.1590/S1984-02922012000300008

Camras, L. A. \& Shutter, J. M. (2010). Emotional facial expressions in infancy. Emotion Review, 2(2), 120-129. http:// dx.doi.org/10.1177/1754073909352529

Cleveland, A., Schug, M., \& Striano, T. (2007). Joint Attention and Object Learning in 5- and 7-Month-Old Infants. Infant and Child Development, 16, 295-306. http://dx.doi.org/10.1002/icd.508

Costa, C. A. (2012). Significações em relações de bebês com seus pares de idade (Dissertação de Mestrado). Universidade de São Paulo, Ribeirão Preto.

Feldman, R. \& Reznick, J. S. (1996). Maternal perception of infant intentionality at 4 and 8 months. Infant Behavioral Development, 19, 483-496. http://dx.doi.org/10.1016/S0163-6383(96)90008-9

Hoehl, S. \& Striano, T. (2010). Discrete emotions in infancy: perception without production? Emotion Review, 2(2), 132-133. http://dx.doi.org/10.1177/1754073909355004

Izard, C. E., Woodburn, E. M., \& Finlon, K. J. (2010). Extending emotion science to the study of discrete emotions in infants. Emotion Review, 2(2), 134-136. http://dx.doi.org/10.1177/1754073909355003

Jonhson, W., Emde, R. N., Pannabecker, B., Stenberg, C., \& Davis, M. (1982). Maternal perception of infant emotion from birth through 18 months. Infant Behavior and Development, 5, 313-322. http://dx.doi.org/10.1016/S01636383(82)80041-6

Knafo, A. \& Uzefovsky, F. (2013). Variation in empathy: the interplay of genetic and environmental factors. In M. Legerstee, D. Haley, \& M. H. Bornstein (Eds.). The Infant Mind: Origins of the Social Brain (pp. 97-121). New York: Guilford Press.

Legerstee, M. (2013). The Developing Social Brain: Social Connections and Social Bonds, Social Loss, and Jealousy in Infancy. In M. Legerstee, D. Haley, \& M. H. Bornstein (Eds.). The Infant Mind: Origins of the Social Brain (pp. 223-247). New York: Guilford Press.

Legerstee, M. \& Markova, G. (2007). Intentions make a difference: Infant responses to still-face and modified still-face conditions. Infant Behavior and Development, 30, 232-250. http://dx.doi.org/10.1016/j.infbeh.2007.02.008

Levandowski, D. C., Piccinini, C. A., \& Lopes, R. C. S. (2008). Maternidade adolescente. Estudos de Psicologia (Campinas), 25(2), 251-263. http://dx.doi.org/10.1590/S0103-166X2008000200010

Lopes, R. C. S., Vivian, A. G., Oliveira, D. S., Silva, C., Piccinini, C. A., \& Tudge, J. (2009). "Quando eles crescem, eles voam": percepções e sentimentos maternos frente ao desenvolvimento infantil aos 18-20 meses. Psicologia em Estudo, 14(2), 221-232. http://dx.doi.org/10.1590/S1413-73722009000200002

Lowe, J. R., MacLean, P. C., Duncan, A. F., Aragón, C., Schrader, R. M., Caprihan, A., \& Phillips, J. P. (2012). Association of maternal interaction with emotional regulation in 4- and 9-month infants during the Still Face Paradigm. Infant Behavior Development, 35(2): 295-302. http://dx.doi.org/10.1016/j.infbeh.2011.12.002

Marin, A. H. \& Levandowski, D. C. (2008). Práticas educativas no contexto da maternidade adolescente: breve revisão da literatura. Interação em Psicologia, 12(1), 107-113.

Marin, A. H., Martins, G. D. F., Freitas, A. P. C. O., Silva, I. M., Lopes, R. C. S., \& Piccinini, C. A. (2013). Transmissão intergeracional de práticas educativas parentais: evidências empíricas. Psicologia: Teoria e Pesquisa, 29(2), 123-132. http://dx.doi.org/10.1590/S0102-37722013000200001

Markova, G. \& Legerstee, M. (2008). How infants come to learn about the minds of others. Zero to Three, 26-31.

Mendes, D. M. L. F. (2009). As expressões emocionais e o desenvolvimento inicial. In M. L. Seidl-de-Moura, D. M. L. F. Mendes, \& L. F. Pessôa (Orgs.). Interação social e desenvolvimento (pp. 71-86). Curitiba: Editora CRV.

Mendes, D. M. L. F. \& Seidl-de-Moura, M. L. (2009). Expressões faciais de emoção em bebês: importância e evidências. Estudos em Psicologia UERJ, 9(2), 307-327. http://dx.doi.org/10.12957/epp.2009.9105 
Mendes, D. M. L. F. \& Pessôa, L. F. (2013a). Comunicação afetiva nos cuidados parentais. Psicologia em Estudo, 18(1), 15-25. http://dx.doi.org/10.1590/S1413-73722013000100003

Mendes, D. M. L. F. \& Pessôa, L. F. (2013b). Emotion, affection and maternal speech in parental care. In M. L. Seidlde-Moura (Org.). Parenting in South American and African Contexts (pp. 130-145). InTech. http://creativecommons. org/licenses/by/3.0

Nelson, C. \& Horowitz, F. D. (1983). The perception of facial expressions and stimulus motion by two- and five-monthold infants using Holograpfic Stimuli. Child Development, 54, 868-877. http://dx.doi.org/10.2307/1129891

Nogueira, S. E. (2009). A comunicação pré-verbal. In M. L. Seidl-de-Moura, D. M. L. F. Mendes, \& L. F. Pessôa (Orgs.). Interação social e desenvolvimento (pp. 101-116). Curitiba, PR: Editora CRV.

Prado, A. B., Piovanotti, M. R. A., \& Vieira, M. L. (2007). Concepções de pais e mães sobre o comportamento parental real e ideal. Psicologia em Estudo, 12, 41-50. http://dx.doi.org/10.1590/S1413-73722007000100006

Ribas Jr, R. C., Seidl-de-Moura, M. L., \& Bornstein, M. H. (2007). Cognições maternas acerca da maternidade e do desenvolvimento humano: uma contribuição ao estudo da psicologia parental. Rev. Bras. Crescimento e Desenvolvimento Humano, 17(1), 104-113.

Slaughter, V., Peterson, C. C., \& Carpenter, M. (2009). Maternal mental state talk and infants' early gestural communication. Journal of Child Language, 36, 1053-1074. http://dx.doi.org/10.1017/S0305000908009306

Tomasello, M. (2003). Origens culturais da aquisição do conhecimento humano: tópicos. Trad. de C. Berliner. São Paulo: Martins Fontes.

Trevarthen, C. (2011). What is it like to be a person who knows nothing? Defining the active intersubjective mind of a newborn human being infant and child development. Infant and Child Development, 20, 119-135. http://dx.doi. org/10.1002/icd.689

Trevarthen, C. \& Delafield-Butt, J. (2013). Biology of shared experience and language development: regulations for the intersubjective life of narratives. In M. Legerstee, D. Haley, \& M. H. Bornstein (Eds.). The Infant Mind: Origins of the Social Brain (pp. 167-199). New York: Guilford Press.

Tuan, Y. (2005). Medo na criança em crescimento. In Y. Tuan. Paisagens do medo (pp. 19-40). São Paulo: Editora UNESP.

Vygotsky, L. S. (1996). Obras escogidas: Psicología infantil. Tomo IV. Madrid: Visor. (Original publicado em 1932).

Vygotsky, L. S. (2007). A formação social da mente: o desenvolvimento dos processos psicológicos superiores. São Paulo: Martins Fontes. (Original publicado no Brasil em 1984).

Autores:

LAÍSY DE LiMA NunES - Doutoranda, Universidade Federal da Paraíba (UFPB).

FABÍOla DE SOUSA BRAZ AQUINO - Doutora, Universidade Federal da Paraíba (UFPB).

POMPÉIA Villachan-LyRA - Doutora, Universidade Federal Rural de Pernambuco (UFRPE).

Endereço para correspondência:

Laísy de Lima Nunes

Rua Capitão Severino Cesarino da Nóbrega, 210, ed. Novo Tempo, apto. 201

Jardim São Paulo

CEP 58051-220 João Pessoa, PB, Brasil

Recebido em: 04.08.14

Aceito em: 02.03.15 